\title{
Formula Electric Vehicle Wheel Hub Design and Optimization for in-Hub Motor in Rear Wheel Drive Configuration
}

\author{
Rohithraj N \\ Mechanical Engineering, \\ PSG Institute of Technology and Applied Research, \\ Coimbatore, India ,
}

\author{
Arun Sundar S \\ Mechanical Engineering, \\ PSG Institute of Technology and Applied Research, \\ Coimbatore, India,
}

\begin{abstract}
A race car primarily aims at maximizing performance and handling. This can be accomplished by selection and design of powertrain, vehicle dynamics and braking in accordance to the requirements of the car. This paper focuses on selection of suitable electrical powertrain, designing and optimizing a wheel hub assembly having minimal weight and satisfying the technical rules provided in the Formula Bharat rulebook. An in-hub motor design was chosen incorporating Plettenberg Nova 15 motors for a Rear Wheel Drive (RWD) configuration. The motor is attached to an epicyclic gear train that provides a reduction ratio while staying within the limitations of the suspension kinematics. The 3D modelling was done using SolidWorks 2016, structural analysis and topology optimization was carried out in ANSYS Workbench 18.1. The epicyclic gear train validation was done using ADAMS. The best possible configuration of the assembly was selected through the iterative optimization technique.
\end{abstract}

Keywords: Formula Bharat, Nova 15, RWD, upright, wheel hub, In-hub motor, suspension kinematics, Epicyclic, structural analysis, Reduction ratio.

\section{INTRODUCTION:}

Formula Bharat is nationwide competition for engineering students. The competition requires a team to design develop and validate a Formula type vehicle that abides by the rules of the competition [1]. Electric cars have become common on tracks during the last years. Our team Velocita Racing [2] have been participating in similar competitions in design and development of electric formula type cars for about three years now. Being a new team, we strive to improve the performance of the car each year to match the counterparts from other teams.

\section{DESIGN METHODOLOGY:}

For the upcoming endeavor the team has decided to opt-in for in-hub motors that are to be wheel mounted. Plettenberg Nova $15 \mathrm{~kW}$ BLDC motors have been selected as the prime mover [3][4] see Table 1.

Table 1. Motor specification

\begin{tabular}{lll}
\hline Parameter & Value & Unit \\
\hline Max Power & 20 & $\mathrm{~kW}$ \\
\hline Rated Voltage & 90 & $\mathrm{~V}$ \\
\hline Max Torque & 30.56 & $\mathrm{Nm}$ \\
\hline Weight & 2.5 & $\mathrm{Kg}$ \\
\hline Shaft Diameter & 18 & $\mathrm{~mm}$ \\
\hline Max RPM & 6000 & $\mathrm{RPM}$ \\
\hline
\end{tabular}

The vehicle sits on $\mathrm{OZ}$ racing 13" center lock magnesium alloys [5] and corresponding Hoosier slicks 20x7.5-13 A2500 [6]. With regards to packaging, there are two options of motor mounting possibilities, either a chassis mounted array or wheel mounted motor array. The sprung mass for the chassis mounted motor configuration is higher than that of a wheel mounted configuration. Also, the unsprung mass for the chassis mounting is lesser than the wheel mounting. The authors from Chalmers [7] university have observed the advantages of incorporating the in-wheel configuration through a vertical dynamics point of view. Results have showed that for a wheel mounted design the vertical excitation of the car provided better damping of the sprung mass, assuming the car has a working passive suspension system with damping. Another added advantage in opting for wheel mounted motors gives the opportunity to eliminate the need for drive shafts and differentials which also reduce the overall sprung mass. Thus, weighing on the various positives, it was decided to opt for a wheel mounted RWD configuration for the drive train of the current vehicle.

\section{OBJECTIVE:}

The assembly is designed so as to incorporate the following components and satisfy the technical requirements,

1. Epicyclic gear train that is coupled to the motor shaft providing a transmission ratio of 3.25 , considering the package space.

2. Upright that houses the in-hub motor [3] and the gear train.

3. Upright should provide mounting provisions for caliper [8] and control arms that define the suspension geometry.

4. A carrier-hub as the final transmission component connecting the planets and the wheel.

5. The wheel is held together with the hub by the use of a central locknut.

\section{EPICYCLIC GEARTRAIN DESIGN:}

An epicyclic gearbox helps achieve the required transmission ratio at a compact packaging space. The design parameters of the transmission were driven by the acceleration and top speed of the vehicle. Gear ratio of 3.25 
was selected based on lap time simulation which allowed a safe design while enough to gain a sufficient competitive advantage. The gears are to be packed within the casing provided in the upright therefore should have a compact design and should have minimum weight. The primary condition of the gear design given by the following expression [9]:

$$
\begin{array}{ll}
\text { 1. } & n=2 *\left(1+\frac{Z_{P}}{Z_{S}}\right) \\
\text { 2. } & Z_{R}=Z_{s}+\left(2 * Z_{p}\right) \\
\text { 3. } & \frac{\left(Z_{S}+Z_{R}\right)}{N_{P}}=\text { Reminder } 0
\end{array}
$$

The planetary gear train offers various possible transmission ratios conditional on the nature of configuration. First up in the design process the nature of input and output of the epicyclic gear train has to be selected which provides the required transmission ratio in the allotted design space, see Table 2.

Table 2. Gearbox Configuration I

\begin{tabular}{ll}
\hline Gear Type & Gear Name \\
\hline Driver & Sun Gear \\
\hline Driven & Planet Gear \\
\hline Fixed & Ring Gear \\
\hline
\end{tabular}

The spur gear incorporated epicyclic gearbox coupled with 6000rpm motor is expected to make the vehicle accelerate through a $75 \mathrm{~m}$ straight stretch of tarmac in 3.21 seconds, which accounts to a peak acceleration of $3.47 \mathrm{~ms}^{-2}$ and top speed of $120 \mathrm{kmph}$. Such a gear train is to have the following parameters, refer Table 3.

Table 3. Gear parameters

\begin{tabular}{ll}
\hline Parameter & Value \\
\hline No of Teeth in Sun Gear & 32 \\
\hline No of Teeth in Planet Gear & 20 \\
\hline No of Teeth in Ring Gear & 72 \\
\hline Module & 2 \\
\hline Diameter of Sun Gear & 64 \\
\hline Diameter of Planet Gear & 40 \\
\hline Diameter of Ring Gear & 144 \\
\hline Final Drive Ratio & 3.25 \\
\hline
\end{tabular}

The 3D modelling of gear was done in SolidWorks (Fig 1) and were checked for meshing and possible gear forces in ADAMS (Fig 2).

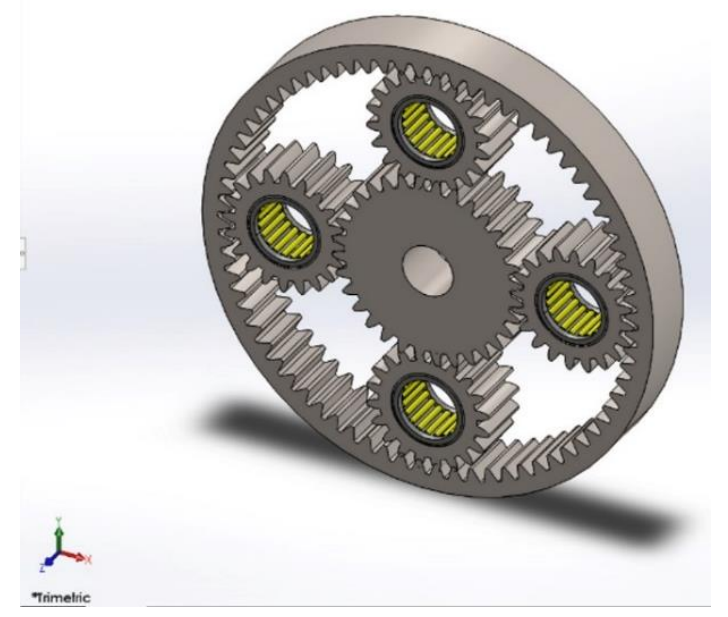

Fig 1. Epicyclic Gear Train Assembly

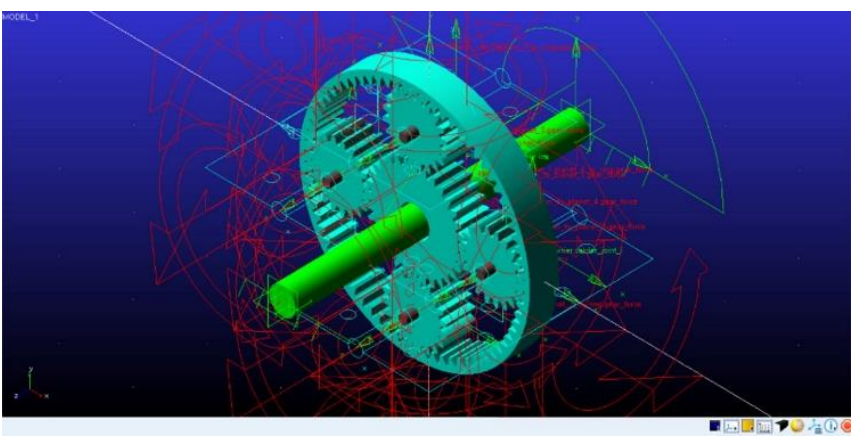

Fig 2. Validation in ADAMS

Post validation of the epicyclic gear train the model was further subjected to structural analysis in ANSYS and the results are shown in Fig 3.

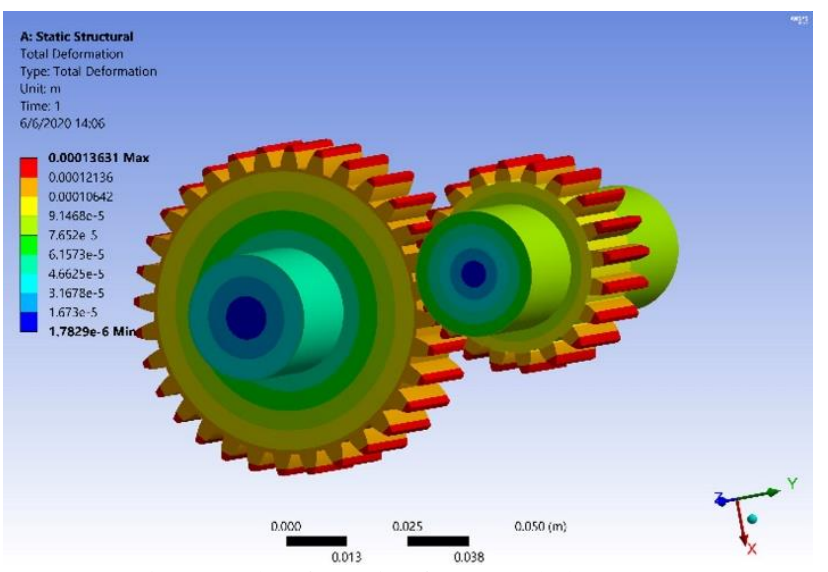

Fig 3. Total Deformation for sun and planet contact

Results have shown that a maximum deformation of $0.1363 \mathrm{~mm}$ for a sun to planet contact, which is well within the acceptable limits. Following the design and validation the bearings were selected accordingly considering the loading, life and dimensional constraints. The planets are to be seated on needle roller bearing [10] and the carrier-hub to be seated on deep groove ball bearing. [11] 


\section{UPRIGHT DESIGN:}

The dynamics and handling of the car is controlled by the suspension system. The springs, shock absorbers, upright, control arms etc., all form a part of the suspension system. Among which the uprights are the most critical part of all. They conform with the kinematics of the suspension system and maintains rigidity of the vehicle. They form the connection between the wheels, brake calipers and rotors, hub, gears, drive shafts, steering arms etc. The uprights are also subjected to high stresses due to the dynamic forces acting on it during acceleration, braking, cornering, unevenness on the track, suspension changes etc. having considered all the above key factors the criticality of the uprights is evident and hence it is expected to withstand the different loading conditions and be non-compliant. Also being a part of the unsprung mass, it should have minimal weight without compromising on reliability and build quality. Abiding to the requirements, after a several iterations the optimized design for upright is shown in Fig 4

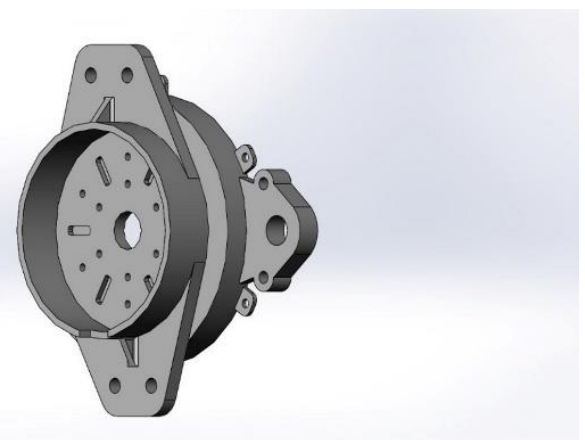

Fig 4. 3D Model of Upright

Types of forces classified and their values as per design are given in Table 4.

Table 4. Force types and values

\begin{tabular}{ll}
\hline Type & Value \\
\hline Cornering Force & $2212.4 \mathrm{~N}$ \\
\hline Braking Force & $3547 \mathrm{~N}$ \\
\hline Accelerating Moment & $104 \mathrm{Nm}$ \\
\hline Vertical Load & $1256 \mathrm{~N}$ \\
\hline
\end{tabular}

Structural analysis was done for two conditions:

1. Cornering and Accelerating

2. Cornering and Braking

Equivalent von-Mises stress contours for both cases of loading are depicted in Fig 5 and 6.

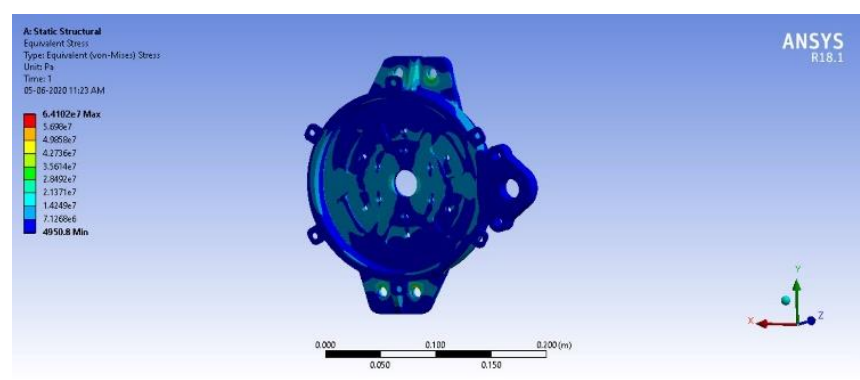

Fig 5, Cornering and Accelerating

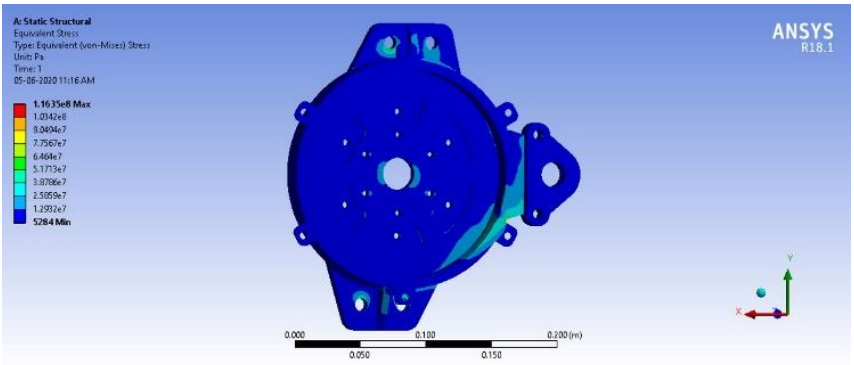

Fig 6, Cornering and Braking

Among the two cases, cornering and braking is found to have the most equivalent von-Mises stress. The deformation and safety factors for both cases are given in Table 5 and Table 6.

Table 5 Cornering and Accelerating

\begin{tabular}{ll}
\hline Type & Value \\
\hline Maximum Deformation & $0.1317 \mathrm{~mm}$ \\
\hline Von-Mises Equivalent & $64.102 \mathrm{MPa}$ \\
\hline Safety Factor & 4.3752 \\
\hline
\end{tabular}

Table 6 Cornering and Braking

\begin{tabular}{ll}
\hline Type & Value \\
\hline Maximum Deformation & $0.8644 \mathrm{~mm}$ \\
\hline Von-Mises Equivalent & $116.53 \mathrm{MPa}$ \\
\hline Safety Factor & 2.4066
\end{tabular}

From the analysis it was evident that the design is safe and fits the purpose.

\section{CARRIER-HUB DESIGN:}

The carrier is an arm connecting the four planet gears and rotates about the common axis. The carrier in this design is also operates as a hub which holds the disc rotor for brakes and the pegs driving the wheel., See Fig 7. The carrier is held by a casing covering the gear box as well and a bearing housing providing rotation of the carrier. The wheel is held in place by a central locknut Fig 8 .

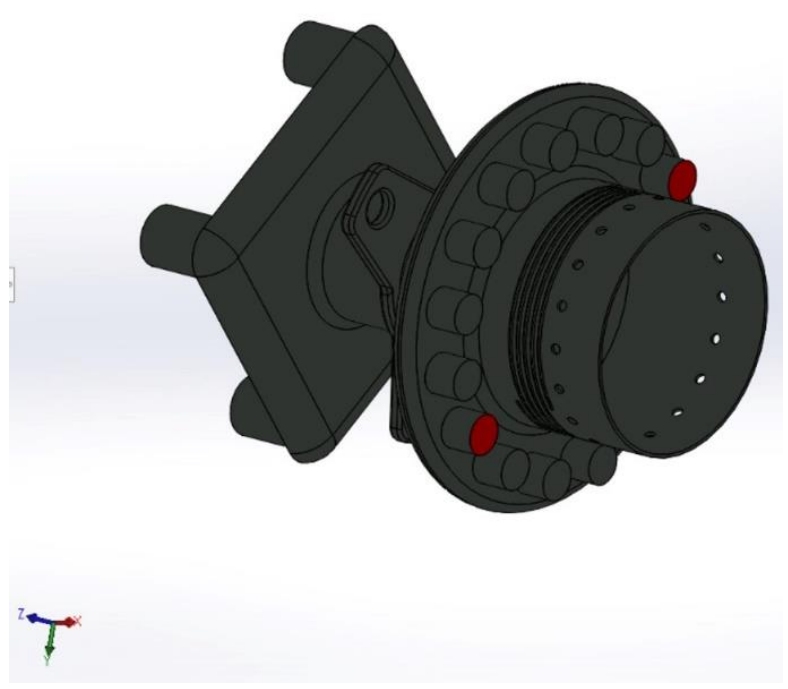

Fig 7. 3D model of Carrier-Hub 


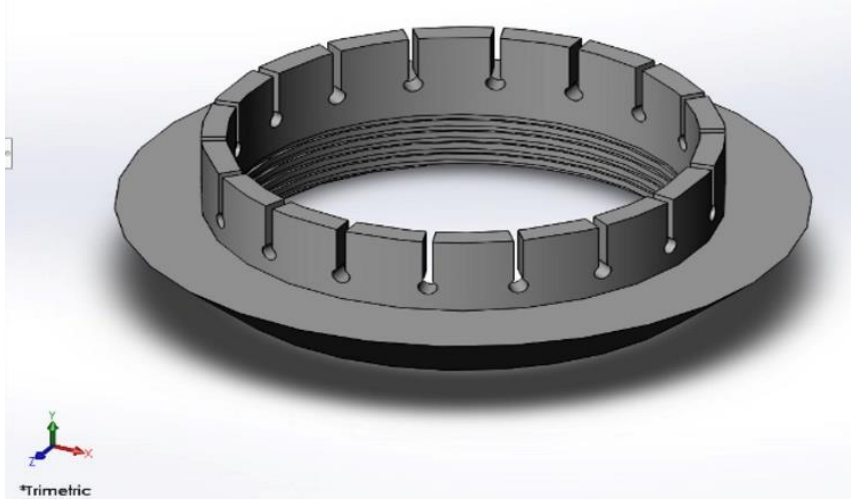

Fig 8. 3D model of Centre Locknut

The carrier is subjected to structural analysis for conditions of acceleration and braking. The nature of forces and their values are given in Table 7

\section{Table 7. Forces for carrier analysis}

\begin{tabular}{ll}
\hline Type & Value \\
\hline Accelerating Moment & $104 \mathrm{Nm}$ \\
\hline Braking Moment & $437 \mathrm{Nm}$ \\
\hline Bump Load & $1500 \mathrm{~N}$ \\
\hline
\end{tabular}

The worst-case scenario was assumed and hence the carrier was subjected to all two loading conditions combined. See Fig 9 and Fig 10

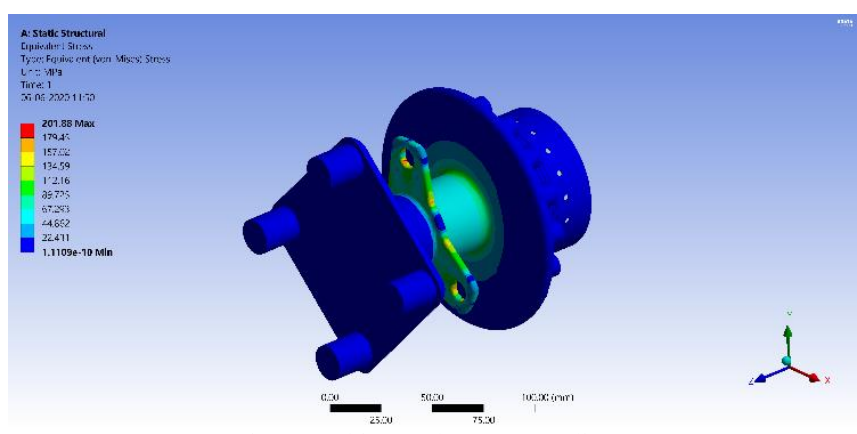

Fig 9. Braking and Bump Loading

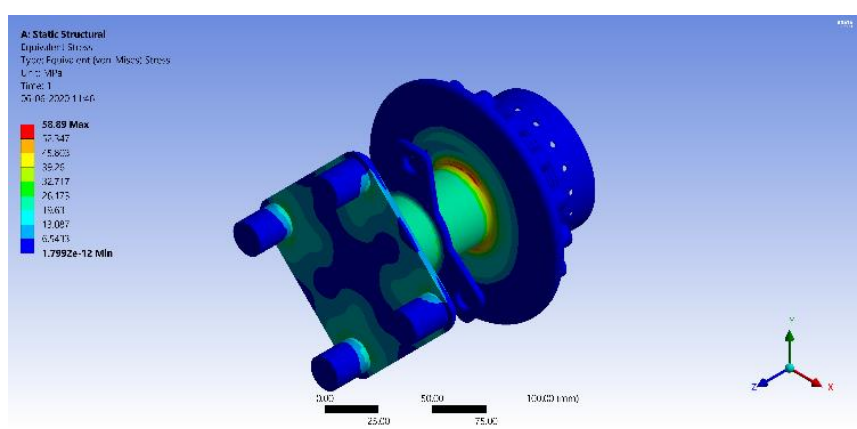

Fig 10. Acceleration and Bump Loading
Deformation and Safety factor are given in Table 8 and Table 9

Table 8. Braking and Bump Loading

\begin{tabular}{ll}
\hline Type & Value \\
\hline Maximum Deformation & $0.2645 \mathrm{~mm}$ \\
\hline Von-Mises Equivalent & $201.88 \mathrm{MPa}$ \\
\hline Safety Factor & 1.387 \\
\hline
\end{tabular}

Table 9. Acceleration and Bump Loading

\begin{tabular}{ll}
\hline Type & Value \\
\hline Maximum Deformation & $0.21385 \mathrm{~mm}$ \\
\hline Von-Mises Equivalent & $58.89 \mathrm{MPa}$ \\
\hline Safety Factor & 4.7546 \\
\hline
\end{tabular}

From the static analysis of the carrier cum hub in shows that the maximum stress is developed during braking and bump loading but was under safe limits.

\section{MATERIAL SELECTION:}

Material selection is based on the application, strength, toughness and machinability. 7075 Aluminum alloy is a strong, workable and resists deformation well. Hence it suits well in high stress applications like the present situation. Being a tough-yet-light metal Aluminum 7075 was chosen for manufacturing the upright, the carrier-hub and the center locknut. For the gears, since they require a harder metal, EN 353 was selected for the purpose. EN 353 due to its higher carbon content is tough and hard and can be used for heavy duty gearing applications. The weights of the components that will result in the assembly are given in Table 10.

\begin{tabular}{ll}
\multicolumn{2}{c}{ Table 10. Component Weight chart } \\
\hline Component & Weight \\
\hline Upright & $1.1616 \mathrm{Kg}$ \\
\hline Epicyclic Gear Train & $1.5 \mathrm{Kg}$ \\
\hline Carrier-Hub & $1.2565 \mathrm{Kg}$ \\
\hline Brake System & $1.238 \mathrm{Kg}$ \\
\hline Motor & $2.5 \mathrm{Kg}$ \\
\hline Locknut & $0.134 \mathrm{Kg}$ \\
\hline Carrier-hub Bearing & $0.37 \mathrm{Kg}$ \\
\hline
\end{tabular}

The total weight of the in-hub assembly (Fig 11) added up to 8.1076 Kilograms.

\section{CONCLUSION:}

Post thorough validation in terms of structural analysis, forces, meshing, manufacturing costs, resources and most importantly safety the designs were finalized. The manufacturing process will be regulated and supervised continuously to ensure proximity to the CAD model. Safety is of at most priority for the team, and as such, once the custom in-hub assembly is completed extensive on-board testing will be done on each system. This recent version of design has in reduction in weight of the assembly when compared to previous year. 


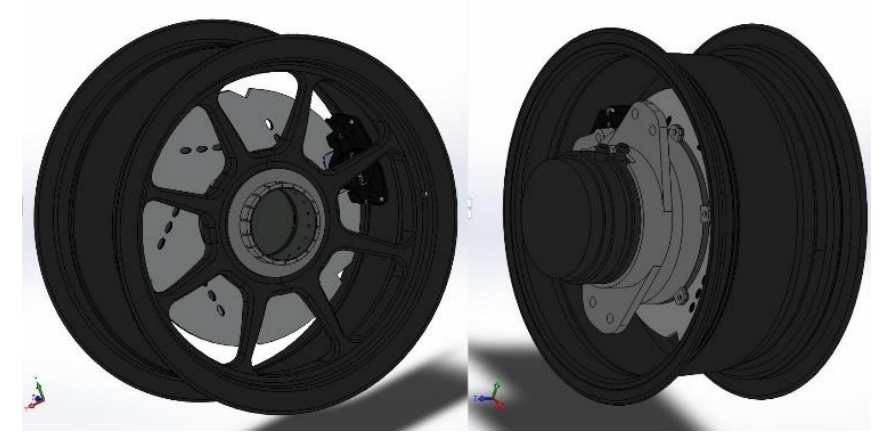

Fig 11. Overall Assembly

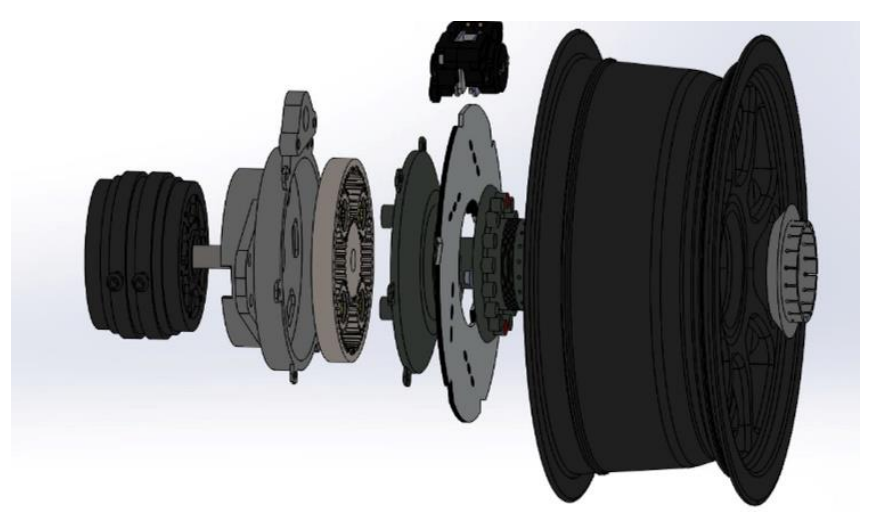

Fig 12. Exploded View of Assembly

\section{ABBREVIATIONS:}

$n$ - Gear Ratio

$Z_{R}$ - No of teeth in Ring gear

$Z_{s}$ - No of teeth in sun gear

$Z_{p}$ - No of teeth in planet

$N_{P}$ - No of planet gears

CAD - Computer Aided Design

Formula Bharat Rules Book https://www.formulabharat.com/downloads/

[2] Velocita Racing, https://velocitaracing.com/

[3] Plettenberg Motoren Official Website "Operating Manual Industrial Motors,"'https://plettenbergmotoren.net/en/products/motor-solutions/motors.

[4] Plettenberg Motoren Official Website "Test Bench Report (NOVA 15/40/B6 P42)" ,https://plettenbergmotoren.net/magic/show_image.php?id=338791\&download=1

[5] OZ Racing Official Website, "OZ Formula Student Magnesium CL wheel," https://www.ozracing.com/images/content/OZ_Drawing_Formula_S tudent_Magnesium_CL.pdf

[6] Hoosier Tires Official Website, "Specification Catalogue,"https://www.hoosiertire.com/assets/Circuit19.pdf

[7] Danielsson, O., Hansson, E., Jonsson, I., Mannerhagen, F., Molander, P., Olofsson, N., Pettersson, J., Pluto, A., \& Sahlin, G. (2013). Design of electrical powertrain for Chalmers Formula Student with focus on 4WD versus RWD and regenerative braking.

[8] Wilwood Disc "Calipers," https://www.wilwood.com/calipers/CaliperList?subname=GP200\%2 0Caliper
[9] Mashadi, B. \& Crolla, D.. (2011). Vehicle Powertrain Systems. Vehicle Powertrain Systems. 10.1002/9781119958376.

[10] SKF Bearing Ltd., "Roller Bearings," https://www.skf.com/group/products/rolling-bearings/rollerbearings/needle-roller-bearings/drawn-cup-needle-rollerbearings/productid-HK\%202020

[11] SKF Bearing Ltd., "Ball Bearings," https://www.skf.com/group/products/rolling-bearings/ballbearings/deep-groove-ball-bearings/productid-W\%206208-2Z 